GRAD

U...

$\mathrm{U}$

408.3

St . K44

$\mathbf{R e}^{2005}$

20

\title{
Development of a Prototype
} Self-Assessment Program in Support of Soldier Competency Assessment

\section{Patricia A. Keenan and Roy C. Campbell} Human Resources Research Organization

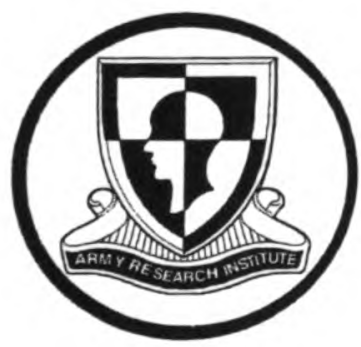

\section{United States Army Research Institute} for the Behavioral and Social Sciences

\section{October 2005}

Approved for public release; distribution unlimited. 